\title{
Pathobiology of tobacco smoking and neurovascular disorders: untied strings and alternative products
}

Pooja Naik ${ }^{1}$ and Luca Cucullo $0^{1,2^{*}}$

\begin{abstract}
Tobacco smoke (TS) is the leading cause of preventable deaths worldwide. In addition to a host of well characterized diseases including chronic obstructive pulmonary disease, oral and peripheral cancers and cardiovascular complications, epidemiological evidence suggests that chronic smokers are at equal risk to develop neurological and neurovascular complications such as multiple sclerosis, Alzheimer's disease, stroke, vascular dementia and small vessel ischemic disease (SVID). Unfortunately, few direct neurotoxicology studies of tobacco smoking and its pathogenic pathways have been produced so far. A major link between TS and CNS disorders is the blood-brain barrier (BBB). In this review article, we summarize the current understanding of the toxicological impact of TS on BBB physiology and function and major compensatory mechanisms such as nrf2- ARE signaling and anti-inflammatory pathways activated by TS. In the same context, we discuss the controversial role of antioxidant supplementation as a prophylactic and/or therapeutic approach in delaying or decreasing the disease complications in smokers. Further, we cover a number of toxicological studies associated with "reduced exposure" cigarette products including electronic cigarettes. Finally, we provide insights on possible avenues for future research including mechanistic studies using direct inhalation rodent models.
\end{abstract}

Keywords: Blood-brain barrier, Cerebrovascular disease, Nrf2, Antioxidant response, Electronic cigarettes, Inflammation, Alternatives, Free radical, Stroke, Diabetes

\section{Background}

Tobacco smoke (TS) is the leading cause of preventable death, accounting for more than 6 million premature annual deaths worldwide and over 480,000/year in the United States alone [1,2]. Smoking and other tobacco use almost always begins at a young age and a large percentage continue to smoke as adults, becoming lifelong smokers. Currently about 5.6 million youths between 0 and 17 years of age are estimated to die prematurely from smoking related illnesses. Both active and passive (second hand) smoking contributes to these high mortality rates with millions of smokers affected by a number of severe, smoking-related morbidities. In the US alone,

\footnotetext{
*Correspondence: luca.cucullo@ttuhsc.edu

1 Department of Pharmaceutical Sciences, Texas Tech University Health Sciences Center, School of Pharmacy, 1300 S. Coulter Street, Amarillo, TX 79106, USA

Full list of author information is available at the end of the article
}

these account for over $\$ 289$ billion extra economic burden including $\approx \$ 133$ billion for direct medical care and $\approx \$ 156$ billion in productivity loss just for the years 2009 2012 [1].

Lung cancer (29\%) [3] and ischemic heart disease such as atherosclerotic diseases of the myocardium and blood vessels (28\%) [4] are the two major fatal morbidities directly associated with smoking. Chronic obstructive pulmonary disease (COPD) $(21 \%)$ and other forms of cancer $(8 \%)$ closely follow. Less common morbidities that have been recently linked to smoking include declined immune functions, rheumatoid arthritis, diabetes mellitus, eye diseases (such age related macular degeneration) and inflammatory bowel disease [5]. Focusing on cerebrovascular disorders, epidemiological studies have associated smoking with the pathogenesis and/or progression of a number of major neurological diseases. These include, but are not limited to, silent 
cerebral infarction (SCI) [6], stroke [7] and small vessel ischemic disease (SVID; due to the pro-coagulant and atherogenic effects of smoking) [8,9] and cerebral aneurysms [10]. There is also a strong correlation between smoking and an increased risk for neurodegenerative disorders such as multiple sclerosis $[11,12]$, Alzheimer's disease, and neurodevelopmental damage during pregnancy [13]. Although some of the neuropathological effects of TS seem to be dependent upon nicotine-activated specific pathways [14], the precise cerebrovascular harmful mechanisms triggered by TS remain largely unclear. However, recent studies clearly suggest that TS can trigger a loss of blood-brain barrier (BBB) function and integrity which is certainly a critical prodromal factor for the pathogenesis of these neurological diseases.

\section{Conceptual focus}

In this review article, we will cover the current knowledge and experimental data concerning the direct effects of tobacco smoking at the brain microvasculature with a special focus on the TS impact on BBB physiology and function. We will also illustrate the determining toxicological factors of TS products including conventional and reduced exposure products such as electronic cigarettes. Using epidemiological evidence along with the limited body of direct toxicology studies, we then discuss the relationship of TS-induced toxicity with the increased risk and early onset of neurological/neurovascular complications in the smoking population. Next, we review current literature that highlights the role of anti-oxidant based defense mechanisms such Nrf2-ARE signaling as well as anti-inflammatory pathways in coping with TSinduced toxicity. In the same context, we will discuss the controversial role of antioxidant supplementation as a prophylactic and/or therapeutic approach to prevent the onset of disease complications or decrease their progression in smokers. Finally, we will provide insights on possible new avenues for future research including mechanistic studies involving direct inhalation rodent models.

\section{The blood-brain barrier}

The BBB is mainly composed of microvascular endothelial cells (ECs) lining the luminal walls of the brain microvessels along with juxtaposed astrocytic end-feet processes and pericytes that support ECs differentiation and maintenance of $\mathrm{BBB}$ properties $[15,16]$. BBB endothelium is functionally distinct from ECs in other vascular beds because they are characterized by little pinocytotic activity, absence of fenestrations (i.e., openings), and distinct distribution patterns of transmembrane transporters. These transporters strictly regulate the passage of nutrients and other essential elements while providing protection (e.g. efflux transporters) from possible harmful substances (both endogenous and xenobiotics). The strict tightness of the BBB ECs largely depend upon the presence of inter-endothelial tight junctions (such as zonulae occludentes-ZO-1, occludin, claudins, and junctional adhesion molecules-JAM) that form a physical barrier between adjacent endothelial cells thus, preventing the passage of hydrophilic substances through paracellular routes [17-19]. Another venue of entry across the BBB is controlled by asymmetrically distributed, carrier-mediated transport systems [20-22]. These allow the passage of water-soluble but biologically important substances (e.g., D-glucose, amino acids, monocarboxylic acids, etc. $[16,17,22])$ from the peripheral circulation into brain parenchyma. The space between the endothelial cells also features junctional complexes of adherens junction (AJ) proteins such as VE-cadherin. Clearly, loss of AJ leads to increased permeability [23] but these proteins primarily assist the TJ which are primary determinants of BBB tightness. The dominant functions of these proteins include cellular adhesion, contact inhibition and polarization of endothelial cells [24].

Apart from $\mathrm{TJ}$ and $\mathrm{AJ}$ proteins, specific efflux systems at the BBB (e.g., P-glycoprotein-P-gp [20], multidrug resistance associate protein 4-MRP4 [22] and breast cancer resistance protein-bcrp $[25,26])$ limit the passage of potentially harmful amphipathic and hydrophobic substances by preventing their entry into the brain $[20$, 27]. These transporters work in concert with several drug metabolizing enzymes (including monoamine oxidases and cytochrome P450s) via activation of the pregnane $\mathrm{X}$ receptor (PXR) also known as the steroid and xenobiotic sensing nuclear receptor) $[28,29]$ to efflux the passage of harmful substances into the brain [17]. Although the expression and functional activity of these metabolic enzymes has not been quantified relative to other organs, their presence at the BBB endothelium has been postulated based on gene expression studies. For example, cytochrome P450 enzymes (e.g., P450 3A4) expressed at the $\mathrm{BBB}$ endothelial level under pathological conditions (e.g., drug-resistant epilepsy) $[28,29]$ were shown to actively metabolize carbamazepine into inactive derivatives in BBB endothelial cells isolated from brain tissue resections of drug resistant epileptic patients. In addition to xenobiotics, these P450 enzymes metabolize endogenous lipids and steroidal hormones [30].

\section{Impact of cigarette smoke on BBB and CNS}

Cigarette smoking is considered a major risk factor for several neurological disorders and neurovascular complications including stroke, SVID and vascular dementia. Preclinical and clinical findings published so far attribute oxidative and inflammatory damage caused by a large and still poorly identified number of highly reactive 
oxidative species (ROS) contained in TS as the primary determinants of cigarette smoke-induced vascular toxicology. In addition, neurological complications such as Alzheimer's disease, multiple sclerosis, stroke, small vessel ischemic disease and vascular dementia [31-38] also report the involvement of ROS and inflammation as central mechanisms initiating and promoting disease progression. Thus, it is a viable possibility that chronic smoking exacerbates the overall damage due to oxidative and inflammatory stimuli and predisposes the end consumer to these neuropathologies.

The BBB is rapidly exposed to this host of harmful toxicants and ROS present in TS which become a critical factor in TS-promoted CNS disorders. The BBB plays the crucial role of a dynamic interface which normally controls the passage of substances (both endogenous and xenobiotics) between the blood and the brain thus maintaining the brain homeostasis. When a cigarette puff is inhaled, a large number of soluble and gaseous components within the smoke rapidly pass through the lung alveoli into the arterial circulation (skipping first pass metabolism) and quickly reach the brain microvasculature. The brain parenchyma is effectively shielded from TS toxicants circulating in the blood by the BBB. However, chronic exposure to these substances may impact $\mathrm{BBB}$ viability and function overtime (e.g., lifelong chronic smokers). A functionally compromised BBB can then enable the onset and/or progression of neuroinflammatory and neurovascular disorders $[39,40]$ which in turn can kick off a vicious cycle of continued BBB impairment.

Despite the strong evidence of an association between smoking and vascular impairment, the impact of cigarette smoking on the $\mathrm{BBB}$ has only been marginally addressed. This is quite evident from the relative small number of basic and translational studies currently available in the literature. For example, the incidence of small vessel ischemic disease (SVID; a pathological condition characterized by loss of BBB integrity and leaky brain microvessels) in chronic smokers was shown to be significantly higher than non-smokers [41]. As a consequence of this disorder, patients typically manifest concerns such as gait problems, urinary continence and cognitive decline. The evidence of a leaky barrier in these patients was determined by measurements of $\mathrm{S} 100 \beta$ (a serum marker of blood-brain barrier integrity [41-44]) plasma extravasation and confirmed by Magnetic Resonance Imaging (MRI) scans showing widespread white and grey matter signals consistent with impaired BBB integrity [41].

In vitro toxicological testing of cigarette smoke using total TS particulate matter or soluble cigarette smoke extracts (CSE) is primarily focused on the lung and the cardiovascular system. However, the gaseous and soluble fractions quickly cross the lung alveoli, move into the arterial circulation and rapidly reach the cerebrovascular network (and the BBB) right away. Current BBB toxicological studies are limited to assessing the harmful impact of whole soluble TS extracts or nicotine; the main tobacco neurostimulant component.

Previous work by our group using whole soluble TS extracts from research tobacco products (such as 3R4F; equivalent to conventional full flavor cigarettes) revealed a host of strong pro-inflammatory responses triggered by cigarette smoke at the BBB endothelial level [45]. The effect was significant both at the transcription and translational levels and included the up regulation of phase 1 and 2 detoxification mechanisms, activation of the antioxidant response pathways [46], up regulation of proinflammatory cytokines, vascular adhesion molecules and increased leukocyte-endothelial interactions [41]. This strong inflammatory response is crucially relevant to define the impact of TS at the cerebrovascular level since vascular adhesion molecules facilitate the adhesion of monocyte to ECs and extravasation across the BBB [47]. Moreover, pro-inflammatory cytokines play a major role in the pathogenesis and modulation of inflammation [48] and have been shown to regulate the trafficking of immune cells across the BBB into the brain by acting as modulator of cytoskeleton $\mathrm{TJ}$ proteins and actin filaments [49]. In fact, a direct assessment of the BBB endothelium revealed a significant down regulation of major $\mathrm{TJ}$ proteins such as ZO-1 and occludin paralleled by release of vascular endothelial growth factor-VEGF (a vasogenic factor that has been reported to play a major role in loss of BBB integrity [50]) and concomitant increase of paracellular permeability [46] (see also Fig. 1).

Apart from the whole soluble TS toxicants which seem to correlate well with oxidative stress generated by TS, nicotine exposure has shown to down regulate $\mathrm{BBB}$ endothelial tight junction protein expression such as ZO-1, occludin, cadherin, and adherens junctional proteins [51-53]. In a separate study by Abbruscato et al. nicotine exacerbated ischemic reperfusion (IR) injury and edema formation in experimental models of stroke [54]. Interestingly, the investigators observed a decrease in $\mathrm{Na}^{+} / \mathrm{K}^{+} / 2 \mathrm{Cl}^{-}$co-transporter activity following IR with prior nicotine and/or tobacco smoke exposure [52, 55]. Furthermore; nicotine has been shown to promote angiogenesis in vitro in HUVECs and HCAECs mimicking the effects of VEGF thus increasing capillary density and stimulating the growth of collateral blood vessels in mouse models of hind limb ischemia [56].

A noteworthy finding is the impact nicotine has on the drug disposition of saquinavir- an anti-retroviral drug used in Human Immunodeficiency Virus (HIV) therapy. The study reported that chronic exposure to nicotine 


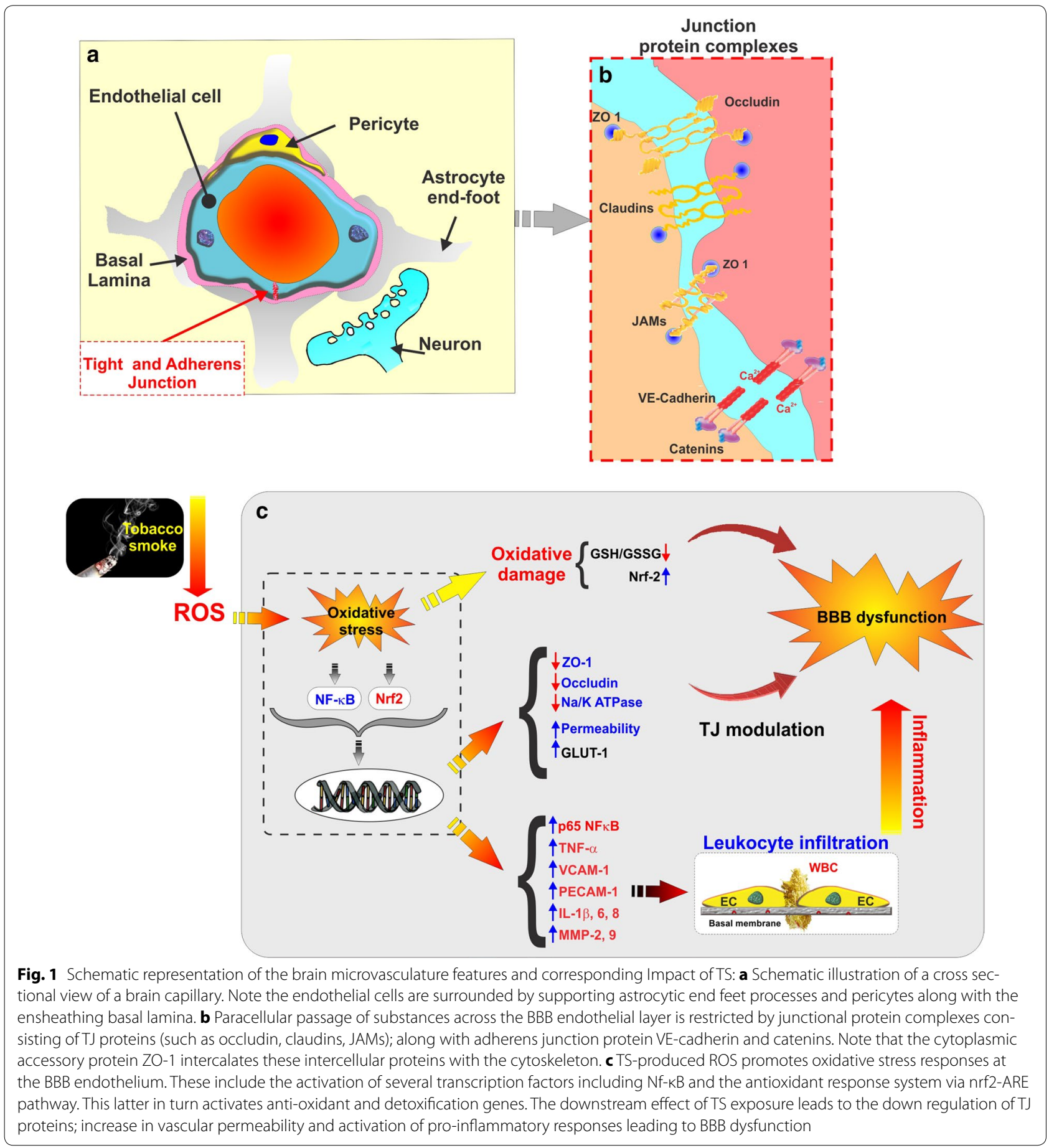

(delivered via subcutaneously osmotic pumps) impaired the activity of efflux transporters such as P-gp along with the loss of TJ protein ZO-1 and Notch-4 expression [57, 58]. However, chronic nicotine exposure did not impede the passage of polar paracellular markers in sucrose perfusion studies. The same group also reported alterations in passive permeability or diffusion of compounds with low extraction values [59]. Although detailed in vivo studies, based on chronic exposure of total whole soluble TS toxicants and their impact on the BBB function and efflux transporters are warranted; so far the reported studies clearly indicate the overall potential of TS toxicants to impact BBB function. 
Regarding the pro-inflammatory activity of TS, elevated levels of leukocytes are commonly observed in smokers [60]. In particular, neutrophils, which secrete free radicals, elastase and collagenase [61], are thought to contribute directly to EC injury. Platelet activation is also frequently observed [62], as confirmed by in vitro and in vivo studies [63]. In conformity to a previous report by Nordskog, release and activity of matrix metalloproteinase-2 and -9 [64] was also significantly increased. MMP-2 and 9 primarily target the $\mathrm{BBB}$ by degrading components of the basal lamina and facilitating immune trafficking into the brain [65]. TS directly promoted the differentiation of monocytes into macrophages independently from the presence of activated endothelial cells. Metalloproteinases such as MMP-9 are known to directly affect BBB integrity and have also been reported in immune cell trafficking $[66,67]$. The importance of these inflammatory events has been described in both in vivo and in vitro settings with the use of human aortic endothelial cells $[68,69]$. Together with local infiltration and activation of circulating immune cells, these processes may contribute to the pathogenesis of vascular inflammatory disorders which have been linked to the onset and/or progression of several neuroinflammatory and neurovascular diseases $[70,71]$. Previous studies from our group have also shown that tobacco smoke exposure impacts BBB endothelial inflammatory response at the gene transcriptional level $[41,46]$. In fact, transcription of inflammatory modulators such as NF-kappaB, RelB and STAT3 (which is also an angiogenesis modulator [72, 73] and a molecular linker for extracellular signals to transcriptional control of proliferation and immune evasion) were significantly upregulated by TS. Furthermore, SAA1 (a potent chemoattractant factor also responsible for the transcription of amyloid A [74]) and APOE (directly related to atherosclerotic diseases and ischemic damage [75]) gene expression were also upregulated. Specifically APOE is responsible for the production of apolipoprotein $\mathrm{E}$, which is essential for the normal catabolism of triglyceride-rich lipoprotein constituents. This polymorphic gene has been studied for its role in several biological processes related to immunoregulation and is associated with elevated cholesterol and risk of atherosclerosis and ischemic stroke.

Further, TS contains high concentrations of nitric oxide (NO) [76], which also can affect BBB integrity. NO plays critical role in controlling vascular tone, leukocyteendothelial adhesion and platelet aggregation. $\mathrm{NO}$ has been shown to modulate BBB function [77, 78] and is directly involved in a number of pathological processes inherent to inflammation. NO has a vasodilatory effect during the early stage of ischemic injury which appears to be protective for the brain [79]. This is early stage endothelial response promoted by eNOS activity is soon followed by activation of inducible NO synthase (iNOS) in inflammatory cells infiltrating the brain as well as the brain microvasculature leading to a massive spike of $\mathrm{NO}$ production (which peaks at 12-48 $\mathrm{h}$ after ischemia). Through a process of redox cycling NO is diverted toward the formation of peroxynitrite followed by production of superoxide anion radicals $\mathrm{O}_{2}^{-}$[80] which propagates inflammation to neighboring districts propagating the damage. This ultimately results in the initiation and progression of vasculo-pathogenic diseases such as atherosclerosis, thrombosis.

Currently, vascular pathogenic processes activated in response to chronic tobacco smoking are far from being fully understood. Although, inflammation as well as oxidative damage have been shown as major determinants of TS toxicity in studies published so far, additional studies both in vitro and in vivo will be necessary to break down the molecular targets and mechanisms involved. This is of critical importance in lieu of recent mechanistic studies outlining the parallel between cerebrovascular toxicity of tobacco smoke, its oxidative potential and the concurrent stimulation of a major antioxidant response system; the Nrf2-ARE pathway [46].

\section{Nrf2-ARE Pathway in cigarettes smoke-induced oxidative stress}

Nuclear factor (erythroid derived 2) like 2 known as NFEL2 or Nrf2 is a cap'n'collar (CNC) basic-region leucine zipper (bZIP) transcription factor which plays a major role in countering oxidative stress [81-83]. Under basal conditions it is usually maintained at a low level in cytoplasm and bound to keap-1 which directs it to proteasomal degradation. Gene polymorphisms in the promoter region, post transcriptional modifications and protein-protein interactions have also been reported to modulate Nrf2 basal activity [84]. Of interest in the current context, however, is the inducible response of Nrf2 by TS-induced oxidative stress via ROS generation.

Under an oxidative stress insult, keap1 is ubiquitinated and Nrf2 becomes free to translocate from its cytoplasmic subcellular location into the nucleus. Upon binding to the antioxidant response element (ARE), it activates the transcription of several downstream genes mainly involved in detoxification and antioxidant processes [83, 85]. The major downstream effectors of the ARE pathway can be classified into the following main categories: (1) detoxification system including Phase I (oxidation/reduction), Phase II (conjugation enzymes) and Phase III (drug efflux transporters) [83, 85]. The Phase I genes are involved in oxidation/reduction/hydrolysis biochemical functions including enzymes belonging to the aldo-keto reductase family, aldehyde and alcohol dehydrogenases, cytochrome $\mathrm{P} 450, \mathrm{NAD}(\mathrm{P}) \mathrm{H}$ : Quinone reductase I (NQO1) and 
carbonyl reductase (CR) to name a few. Substances then enter Phase II where they are conjugated to bulky polar groups such glutathione, glucoronic acid, sulfate or glycine and converted into more readily excretable forms. Apart from these biochemical reactions, potentially harmful compounds are also kept out of the cell through the activity of efflux transporters belonging to the ATP binding cassette (ABC) family; (2) antioxidant system (including glutathione-GSH and thioredoxin); (3) heme and iron metabolism; (4) Carbohydrate and lipid metabolism; (5) cross talk between transcription factors.

Many studies report high transcriptional activity of these factors in several disease models of acute and chronic oxidative or inflammatory injuries in the brain as well as other peripheral organs. These include disorders related to oxidative and/or inflammation such as diabetes $[86,87]$, ischemia reperfusion injuries $[88,89]$, cardiomyopathies and heart failure [90], liver fibrosis [91], and chronic kidney disease [92]. Activation of the Nrf2 pathway and up regulation of several downstream effector proteins has also been reported specifically due to cigarette smoking on resident macrophages, lung bronchial and alveolar epithelium and lung fibroblasts of chronic smokers [93]. Nrf2 activation has been shown to play a major coping role against the onset and progression of COPD and emphysema- major disorders associated with smoking $[81,94,95]$.

Unfortunately, the vast majority of current literature concerning the mechanistic details of TS toxicity primarily covers the pulmonary and cardiovascular systems leaving the cerebrovascular system poorly understudied. This remains a critical issue to be addressed since the importance of the Nrf2-ARE pathways at the brain microvascular level have been clearly emphasized by a number of recent studies focused on cerebrovascular oxidative stress injuries. These injuries include stroke (both global and focal ischemia) [96], subarachnoid brain hemorrhage [97], amyotrophic lateral sclerosis (ALS) [98], multiple sclerosis (MS) [99] and Alzheimer's disease (AD) [100] and diabetes [101, 102]. Interestingly, the impact of Nrf2 signaling has been reiterated in several recent, preclinical studies which have clearly shown that boosting antioxidant pathways through Nrf2 enhancers or antioxidant supplements such as docosahexaenoic acid (DHA), resveratrol, bicyclol can be beneficial in neuropathologies such as cerebral stroke [103-105]. Nrf2 has shown to play a cytoprotective role against TS exposure in BBB endothelial cells. Our group has observed nuclear translocation of $\mathrm{Nrf} 2$ followed by increased transcription (and translation) of detoxification enzymes and anti-oxidants in response to TS exposure [46].

In contrast, a number of clinical and preclinical studies concerning the effects of chronic smoke have revealed that the organs exposed to TS manifested a defective and compromised Nrf2 signaling [106, 107]. One such study highlighted the inhibition of the Nrf2/ARE pathway due to cigarette smoking in peripheral mononuclear cells of young heavy smokers which promoted inflammation and exacerbated damage [108].

Unfortunately, to date, the pathobiology of cigarette smoking at the brain and brain microvascular level is still poorly understood. How these pathways are activated and if chronic TS exposure can impact Nrf2-based mechanisms operating at the BBB level is a question still open for investigation. It is therefore evident that there is urgent need to identify new avenues of intervention for reducing the risk of cerebrovascular disorders in smokers and, perhaps, accelerate the recovery of the antioxidant system during smoking cessation.

\section{Antioxidant supplementation in smokers: where do we stand today?}

Tobacco smoke generates superoxide and other reactive oxygen species which promote DNA strand breakage [109-112], release of nitric oxide (NO) and antioxidant depletion (e.g., ascorbic acid). Under normal conditions, ROS are cleared by the intracellular action of superoxide dismutase (SOD), catalase, glutathione (GSH) peroxidase [113] or extracellular antioxidant vitamins such as ascorbic acid (vitamin C), and $\alpha$-tocopherol (vitamin E) [114-117]. However, environmental factors including active and passive TS spawn sustained high levels of ROS beyond the ability of the human body to effectively eliminate them. In fact, several studies have shown that chronic smokers suffer from antioxidant shortages caused by increased anti-oxidative mobilization evoked by TS [118-120]. Over time (e.g., chronic smokers) this imbalance is likely to promote oxidative damage both to cells and tissues. A recently published study by our group [45] has demonstrated that TS contains high concentrations of NO and ROS leading to the initiation and progression of various vasculopathies (e.g., atherosclerosis, thrombosis) as well as BBB damage. Indeed, the current scientific opinion considers ROS-mediated pathways to contribute significantly to the pathogenesis of many neurological diseases. This hypothesis is strongly supported by in vivo and in vitro experiments where antioxidant supplementation prevents oxidative damage and inflammation induced by cigarette smoke. Even the Food and Nutrition Board of the National Academy of Sciences has established a higher recommended dietary allowance (RDA) of vitamin C for smokers (over $200 \mathrm{mg} /$ day versus the recommended $90 \mathrm{mg} /$ day for non-smokers). However, clinical studies have shown a number of contrasting results with in vitro and/or in vivo studies regarding the therapeutic effect of antioxidants in a number of 
neurovascular/neurodegenerative disorders [121-125]. This makes it challenging to argue for or against the prophylactic and/or therapeutic use of anti-oxidants in smokers. Recent observations suggest that ROS are key mediators of BBB breakdown [126] and antioxidant supplementation has proven to be beneficial in alleviating a loss of BBB integrity and a vascular inflammatory response in smoke-exposed in vitro BBB cultures [127]. Although there is still no unequivocal evidence that an increased intake of antioxidant nutrients can effectively counteract TS toxicity, there is supporting data suggesting that antioxidants may prove to be effective scavengers of exogenous (TS-like)-derived ROS [128]. For example, vitamin $C$ prevents histamine release and increases the detoxification of histamine [129], thus acting as an anti-inflammatory agent as well as a potent antioxidant. Vitamin $\mathrm{E}$ on the other hand has been shown to be cardioprotective against tobacco smoke-induced peroxidative damage [130-132] and can be a beneficial adjuvant in the treatment of seizures, diabetes and in the reduction of post-ischemic damage [133-136]. Recently published in vitro studies by our lab have clearly shown that both vitamin $\mathrm{C}$ and $\mathrm{E}$ can effectively protect the $\mathrm{BBB}$ against TS-generated oxidative damage [127]. Nevertheless, at this point the use of antioxidants (including Nrf2 enhancers) needs to be considered with caution. To illustrate this, in most cases there is not a far reaching consensus in the clinical setting regarding dosing parameters, (including frequency of administration). Recently published preclinical studies also indicate that cancerous cells prioritize Nrf2 activation to promote their survival from antioxidant damage $[137,138]$. Furthermore, high-mobility group protein B1 (HMGB1; a mediator of inflammation produced by necrotic tissue and activated immune cells) appears to be involved in the post-ischemic inflammatory response and has been correlated to poor functional outcome [139-141]. Because the redox state of the intra- and extracellular environments control the activity of HMGB1-mediated pro-inflammatory signaling [142, 143], post-ischemic administration of antioxidants (therapeutic administration) may instead prolong and intensify the pro-inflammatory stimulation at the site of injury by neutralizing the ROS required to abate HMGB1 activity. Considering these premises, it is clear that more detailed and well-designed/standardized studies will be necessary to solve this impasse.

\section{Working around cigarette toxicity from an industry perspective}

\section{Reduced exposure cigarette products}

Cigarette smoke consists of about 7000 different chemicals and potential toxicants which may be included in either the gas and/or the particulate fractions of TS. Tar is defined as the dry solid residue deriving from the combustion of tobacco which yields the particulate fraction of cigarette smoke. This is often termed as TPM which contains nicotine as well as numerous carcinogens, chlorinated dioxins, furans metals, poly aromatic hydrocarbons (PAH), nitrosamines, terpenoids, and paraffin waxes $[144,145]$. The gas phase of cigarette smoke includes gases of combustion such as carbon dioxide $\left(\mathrm{CO}_{2}\right)$, carbon monoxide $(\mathrm{CO})$, nitrogen $\left(\mathrm{N}_{2}\right)$, oxygen $\left(\mathrm{O}_{2}\right)$, hydrogen cyanide $(\mathrm{HCN})$, hydrogen sulfide $\left(\mathrm{H}_{2} \mathrm{~S}\right)$, nitric acid, acetone, acrolein, acetaldehyde, methane, ammonia, methanol, along with hydrocarbons, gas phase nitrosamines [(N-nitrosoanabasine (NAB), N-nitrosoanabatine (NAT), 4-(methylnitrosamino)-1-(3-pyridyl)-1-butanone (NNK), and nitrosonornicotine (NNN)] and carbonyl compounds [144]. In addition, exposure to these substances can increase intracellular levels of ROS through enhanced mitochondrial activity [146-149]. This ultimately can lead to the formation of adducts at lipids, proteins and DNA level such as 4-hydroxy-nonenal (4-HNE) and lipid peroxidation products [150-152], protein carbonyls $[153,154]$ and DNA adducts $[150,155]$ respectively.

Due to the complex nature of identifying and determining these toxicants, which may vary according to the fabrication procedure of the various cigarette brands and lack of central control in their manufacture, the FDA initiated an independent center dedicated to the production and distribution of standardized research tobacco products (reference cigarettes) in 2009 reflecting the main cigarette denominations currently available in the market (e.g., 3R4F-full flavor; 1R5F, light flavor). The tobacco industry has developed "reduced exposure" and "light" cigarettes containing lower levels of nicotine, nitrosamines or other chemicals deemed to be potentially toxic. However, the underlying claim that these products are safer than conventional cigarettes is not supported by experimental and/or clinical data. Recent smokeless tobacco products are marketed to current and "potential" smokers as a safer alternative to conventional products. At the same time, these "light" products also contain a certain amount of tobacco specific nitrosamines. There is a significant difference between these "light" cigarettes versus products that deliver tobacco-free nicotine, such as nicotine replacement therapies (NRT's, e.g., nicotine gum, lozenge and inhaler) or electronic cigarettes (e-cigarettes).

Recent reports using whole soluble TS extracts from conventional and reduced exposure products (including ultralow nicotine-ULN-cigarettes obtained from National Institute of Drug Abuse-NIDA) revealed that the total oxidative and nitrosative capacity as well as proinflammatory activity of ULN (a cigarette containing 
negligible nicotine but quantities of tar comparable to conventional full flavor products) and nicotine free- NF (non-tobacco based) cigarettes were comparable or even worse than conventional cigarettes [45] thus negatively affecting the brain microvascular endothelium $[45,46$, 156]. This creates quite a confusion as to what extent and in which form these reduced exposure products are to be considered safer than their conventional counterparts.

\section{E-cigarettes}

Electronic (e-) -cigarettes are members of the recently marketed electronic nicotine delivery devices (ENDDs). E-cigarettes can be primarily described as electronic, smokeless, nicotine delivery systems simulating cigarette smoking independently of the combustion of tobacco. There are at least 400 different brands of e-cigarettes currently available in the market (see Table 1 for a list of brands) [157]. E-cigarettes contain a fluid-filled cartridge (including numerous ingredients such as vegetable glycerin (VG) responsible for the visible vapor, propylene glycol (PG) serving as a flavor diluent, nicotine, menthol and other flavoring agents), an atomizer (which vaporize the e-liquid by heat) and a power source consisting of a rechargeable battery that charges the atomizer (see Fig. 2). Puffing on the e-cigarette vaporizes the fluid, allowing for the appearance of a "vape" which is delivered to the airways and from there across the lung alveoli into the circulatory system. To date, about three generations of e-cigarette designs have come up in the market with higher battery capacities, more heating power and sophisticated models although relying on the same basic components and principles highlighted above.

Nicotine, the main vape component, is present in the maximum range of $20 \mathrm{mg} / \mathrm{ml}$ [158]. The vapor formation after heating of the e-liquid is not consistent. It is dependent on the product design, and puffing parameters including puffing rate/duration/volume. Nevertheless, the absorption of nicotine is reported as considerably less

Table 1 List of brand of e-cigarettes currently available in market

\begin{tabular}{|c|c|c|}
\hline E-cigarettes & Design features & $\begin{array}{l}\text { Popular e-cigarette products } \\
\text { under the Brand }\end{array}$ \\
\hline Vapor Fi & $\begin{array}{l}\text { Two-piece sophisticated designs } \\
\text { Selection of refillable tank-style e-cigarettes with good vapor } \\
\text { production } \\
\text { Offers over } 30000 \text { flavors } \\
\text { Range of tank sizes and battery power } \\
\text { Variable voltage/airflow }\end{array}$ & $\begin{array}{l}\text { Express starter and Pro starter kit for beginners } \\
\text { VaporFi Rocket—-for more experienced users } \\
1 \text { Rocket Tank with } 1 \text { dual coil and fully adjustable airflow control } \\
\text { Vox II mod-stronger vape } \\
50 \text { watts of power vaporizer (adjustable) }\end{array}$ \\
\hline V2 Cigs & $\begin{array}{l}\text { Two-piece design with disposable as well as refillable versions } \\
\text { Newer line of product designs available includes the V2 Pro } \\
\text { Makes their own e-liquid with } 24 \text { flavor options } \\
\text { Provides battery options with both manual as well as automatic } \\
\text { version }\end{array}$ & $\begin{array}{l}\text { EX line of e-cigarettes are the top miniatures, pen-style e-cigarettes } \\
\text { V2 Pro series } \\
\text { Cartridge recognition to optimize the temperature of the atomizer } \\
\text { Can vaporize three types of ingredients } \\
\text { V2 Disposables and Zig-Zag }{ }^{T m} \text { are disposable e-cigarettes }\end{array}$ \\
\hline Green smoke & $\begin{array}{l}\text { Two-piece design disposable cartomizer system in a range of } \\
\text { flavored cartridges } \\
\text { Designed for beginners }\end{array}$ & $\begin{array}{l}\text { FlavorMax }{ }^{T m} \text { cartridge holds the e-liquid and the unit } \\
\text { Available in different sized starter kits and packs }\end{array}$ \\
\hline Halo cigs & $\begin{array}{l}\text { Halo Cigs offer a well-built product with mainly two designs (Halo } \\
\text { G6 e-cig. and Triton Vape pen) } \\
\text { Makes their own e-liquid }\end{array}$ & $\begin{array}{l}\text { Halo G6 rechargeable e-cigarette } \\
\text { Leak proof and refillable e-cig cartomizers } \\
\text { Different size tank options } \\
\text { Triton vape pen } \\
\text { e-cig with a leak-proof vape tank } \\
\text { Variable voltage long-lasting batteries }\end{array}$ \\
\hline Apollo & $\begin{array}{l}\text { Advanced clearomizer (cartomizers with clear bodies) technology } \\
\text { Makes their own e liquid ( } 25 \text { flavors available); Refillable as well as } \\
\text { disposable versions } \\
\text { Range of battery options from low to higher power output }\end{array}$ & $\begin{array}{l}\text { Extreme kit (low battery power for new users) } \\
\text { Endevour kit (Intermediate battery power) } \\
\text { Vtube kit (maximum vape/battery power with variable voltage } \\
\text { option; generally, for heavy smokers) } \\
\text { Apollo Disposable and E-cigar } \\
\text { Disposable products }\end{array}$ \\
\hline Blu Cigs & $\begin{array}{l}\text { Two-piece sleek design in disposable or prefilled designs (with blu } \\
\text { Tank }{ }^{T m} \text { or flavor cartridges) } \\
\text { Signature blue LED tip: Lights up to let you know that your blu } \\
\text { e-cig is working } \\
\text { Silicone tip: Intake maximizes each draw }\end{array}$ & $\begin{array}{l}\text { Blu rechargeable e-cigarette (blu flavor cartridge with rechargeable } \\
\text { battery that charges in the USB chargeable pack); } \\
\text { PLUS + rechargeable }{ }^{\mathrm{TM}} \text { (6-hole tip, more powerful } \\
\text { PLUS + rechargeable battery and blu }{ }^{\mathrm{TM}} \text { tank) } \\
\text { Blu }{ }^{\mathrm{TM}} \text { disposable electronic cigarettes }\end{array}$ \\
\hline EverSmoke & $\begin{array}{l}\text { Looks and feel like a real cigarette } \\
\text { Two battery sizes and range of flavored cartridges with a Silicone } \\
\text { Tip } \\
\text { VaporFlo }^{\text {TM }} \text { technology for smooth draw }\end{array}$ & $\begin{array}{l}\text { EverSmoke Electronic Cigarette (tobacco, menthol and other } \\
\text { flavored rechargeable cartridges) } \\
\text { Available in different sized starter kits and packs }\end{array}$ \\
\hline
\end{tabular}




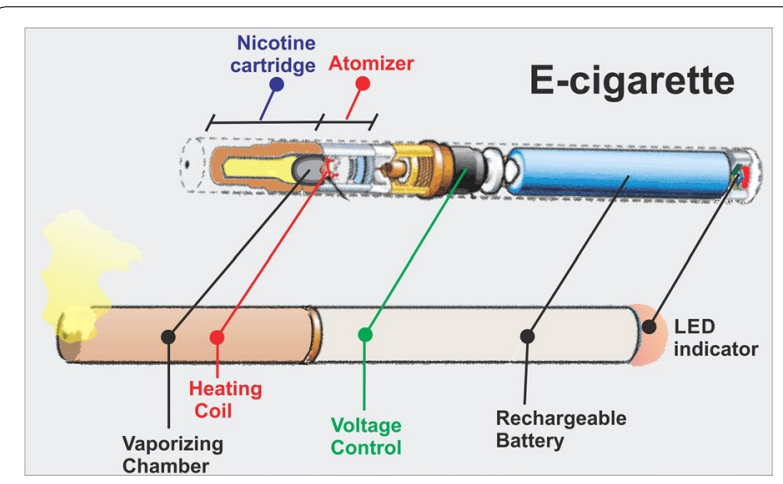

Fig. 2 Schematic illustration of a typical e-cigarette: This device mainly consists of a cartridge containing nicotine dissolved in an e-liquid which also contains flavoring agents; an atomizer that vaporizes the e-liquid and a rechargeable battery (sometimes with a LED indicator) that provides power to the atomizer. The atomizer and the cartridge are sometimes collectively called the cartomizer. The battery output and the resistance of the heating coils determine the vaping capacity of the device

than conventional "combustion-based" counterpart products. Other major components of the e-liquid are propylene and diethylene glycol. Release of these glycols in the vapor is estimated to be with-in safe limits based on some recent reports [159]. However, whether they undergo further physicochemical modification (by the heat necessary to vaporize the e-liquid) into more harmful compounds has not been investigated. Further, there are no defined parameters and established guidelines concerning preparation of the e-liquids and their composition which adds serious safety concerns regarding e-cigarettes.

Increasing the market appeal is their wide range of flavoring agents that can be added to the e-liquid mix such as vanillin, cinnamon, various fruits, menthol, etc. to name a few. These flavoring agents which are proven safe for use in food or confectionary products (ingested) are assumed to be equally safe when vaporized in the form of e-liquids (inhaled). Limited but steady evidence clearly suggests that these flavoring chemicals are present beyond the National Institute for Occupational Safety and Health (NIOSH) safety range and can be a potential irritant when directly inhaled [159-162].

\section{Toxicological data currently available about e-cigarettes}

First introduced into the consumer market in 2005, the global market for ENDDs has rapidly expanded. It has been predicted that within the next decade, sales of ENDDs will surpass that of traditional tobacco-based cigarettes. In 2011, it was estimated that $21 \%$ of US adult cigarette smokers had tried an ENDD [163] which are also quite popular among adolescents and young adults
[164]. The rapid rise of ENDD use has divided the public health and tobacco control community [165, 166]. Although there is potential for public health harm reduction through decreased use of combustible tobacco products $[167,168]$, there are significant concerns about the limited scientific information with respect to the short and long-term effects on human health as well as their intrinsic potential to attract new and former smokers. A high percentage of former smokers are reported to choose e-cigarettes in an effort to quit smoking and/or to allow for smoking in situations where traditional cigarettes are not allowed [169] due to the popular perception of their relative safety [170-173]. Thus, the addictive potential of e-cigarettes is also a major concern.

A critical barrier for the Food and Drug Administration's (FDA's) Center for Tobacco Products (CTP) regulation of all types of cigarettes is the identification of constituents that are harmful to human health. Sadly enough, clinical and preclinical studies supporting the conceptual claims that e-cigarettes are significantly safer than conventional tobacco products are not backed by a body of research evidence. There are a handful of toxicological studies on e-cigarettes that have mainly focused on limited cytotoxicity assessments without considering the detailed vapor composition inhaled by the end-user [161]. Moreover, these studies are limited and to date, have only been performed in vitro on a limited number of cell phenotypes such as pulmonary fibroblasts, bronchial epithelial cells, embryonic stem cells, and neural stem cells [174-176]. Although these reports suggest e-liquids to be safe, there are some observed differences in cytotoxicities attributed to the flavors used. Apart from cytotoxicity assays there are also some chemical assay reports suggesting that, in respect to the content of tobacco specific nitrosamines (TSNAs), carbonyls, volatile organic compounds (VOC) and heavy metals, e-cigarettes are relatively safer [177]. However, analyses of the e-liquid revealed the presence of residual aromatic hydrocarbons, formaldehyde, acetone, minor tobacco metabolites (e.g., anabasine, myosmine, $\beta$-nicotyrine), propylene glycol, diethylene glycol, and tobacco specific nitrosamines including carcinogens in a wide range of concentrations, thus suggesting a lack of standardization of the raw materials and/or manufacturing processes $[159,161]$. Further, some constituents of e-cigarette vapor (e.g., flavoring agents) not present in conventional tobacco smoke have been shown to be cytotoxic in embryonic/adult cellular models [178] and/or represent a possible environmental hazard such as copper [179].

Thus, there are many brands of e-cigarettes currently available in market (as illustrated in Table 1). Due to lack of current regulatory systems each brand produces its own e-liquids which differ for composition, including 
flavoring agents, nicotine concentration, solvent constituents such as propylene glycol and vegetable oils as well as different levels of heating power. These many variabilities in e-cigarette brands may directly impact the toxicity profile of the final products. These warrant for comparative toxicological studies which will be necessary to inform the FDA and generate common manufacturing guidelines. In this regard, the most recent safety studies have been limited to the analysis of heating byproduct derivatives and corresponding direct toxicological assessments (both qualitative and organ specific) [179-181]. Direct vaping of the e-liquid and inhalation studies using preclinical animal models first requires standardization of methods and delivery of the vape to mimic common inhalation patterns of e-cigarettes in the end user. Only then can short and long term toxicological studies on e-cigarettes be reliably planned and executed. Moreover, these toxicology studies need to address not only the primary sites of inhalation (such as the oral cavity, lung mucosa and the cardiovasculature) but also should be extended to brain and the brain microvasculature. Such preclinical toxicological studies are essential to support the regulatory authorities and to set quality standards of this product with the concern of public health in mind.

\section{Unknown health impacts and new regulatory challenges regarding e-cigarette}

The Family Smoking Prevention and Tobacco Control Act (FSPTCA) gave the FDA the authority to regulate the manufacture, marketing and distribution of tobacco products. This authority includes the review of new and modified tobacco products prior to their introduction to the market and to establish standards for tobacco products. A recently conducted worldwide survey found that both former smokers and current heavy smokers initiated e-cigarette use based on the perceived benefits of lack of toxicity and negligible effects of second hand smoking exposure for their families [182] versus the use of regular products. These surveys clearly indicate the end-consumer is making serious health decisions based on the commercial claims of these products. Consumers assume that e-cigarettes prolong abstinence and/or promote a more effective smoking cessation program than RTS. However, current clinical studies are inconclusive $[183,184]$ and, therefore, e-cigarettes provide uncertain benefit in quitting smoking. The CTP division of the FDA currently monitors and reviews cigarettes, roll-your-own tobacco and smokeless tobacco. However, due to the alarming concern over the use of e-cigarettes, it initiated public forums to report adverse events and toxicities associated with the use of new electronic devices. In addition, it has recently proposed a rule to extend the regulation of these newly "deemed" products (such as e-cigarettes) which are incorporated under CTP regulatory monitoring.

\section{Conclusion and future perspectives}

Although, epidemiological evidence and clinical studies have clearly shown that tobacco smoking is a major risk factor for the pathogenesis of several neuro-inflammatory and neurovascular disorders $[6,185,186]$, detailed toxicological and mechanistic studies focused on TS effects at the brain and brain microvasculature are quite scarce. The few basic studies addressing this crucial issue have shown that TS exposure is likely to impact BBB physiology and functions by promoting oxidative stress damage and inflammation. Although indicative of the potential TS toxicity at the BBB, these studies have been limited at large to in vitro settings following acute or limited chronic exposure which may not fully recapitulate the complex dynamics of a physiological setting. Studies in vivo have been limited to a handful of constituents (mainly nicotine) contained within the several thousands of compounds found in TS. Therefore, there is a clear lack of knowledge in regard to TS cerebrovascular toxicity that needs to be addressed. Direct chronic smoke inhalation studies in vivo along with assay of the additional physiological alterations (e.g., blood hemostasis, neuroinflammatory biomarkers, etc.) will be necessary to gather realistic data in a setting that more closely mimics the smoking patterns of the end user. Additional mechanistic insights will enable us to elucidate the antioxidant as well as inflammation based cytoprotective mechanisms at the BBB level and their overall capacity to sustained the oxidant load generated by TS as well as other oxidative stimuli. This will take us a practical and important step forward in understanding the health risk associated with tobacco smoking regarding the onset of neurovascular and neuro-inflammatory diseases such as cerebrovascular stroke, diabetes, Alzheimer's disease, SVID, vascular dementia and multiple sclerosis. These data could be also used to identify a number of putative prognostic biomarkers to assess the smoker risks for the pathogenesis and/or progression of neurological disorders. Apart from these studies largely focused on the mechanistic component, therapeutic studies aimed at the betterment of health outcomes of the smoking population are equally crucial. In that direction, the use of Nrf2 enhancers has demonstrated impressive results to improve cerebrovascular pathologies such as stroke outcomes [103, 187]. Nrf2 driven activation of ARE pathway may be compromised in a BBB that is chronically exposed to tobacco smoke (TS); which in an event of cerebrovascular ischemic insult may lead to exacerbated loss of BBB integrity/function and secondary brain injury. These enhancers (or activators) can potentially benefit the health of the smokers through improved anti-oxidant capacity 
along with smoke cessation or reduction aids currently available in the market.

Concerning reduced exposures tobacco products, currently available toxicological studies examining the cerebrovascular system and the CNS are very scarce. For products recently introduces in the consumer marker such as e-cigarettes, the lack of toxicological data is even more dramatic considering that the very limited number of studies published so far focus most exclusively on the respiratory system. In addition, standardized toxicological testing paradigms to compare e-cigarettes versus traditional tobacco products have not been developed. The urgency of filling this gap is strongly dictated by a number of population-based studies suggesting that the use of e-cigarettes (especially among young individuals) will soon surpass that of conventional cigarettes. Enforcement of Good Manufacturing Practices is also a "must" to ensure quality standards in the preparation of the tobacco products including e-liquids and safety of the main raw materials utilized.

\begin{abstract}
Abbreviations
CO: carbon monoxide; $\mathrm{N}_{2}$ : nitrogen; 4-HNE: 4-hydroxy-nonenal; ABC: ATP binding cassette; AD: Alzheimer's disease; ALS: amyotrophic lateral sclerosis; ARE: antioxidant response element; BBB: blood-brain barrier; Bcrp: breast cancer resistance protein; $\mathrm{CO}_{2}$ : carbon dioxide; $\mathrm{COPD}$ : chronic obstructive pulmonary disease; CR: carbonyl reductase; CTP: center for tobacco products; DHA: docosahexaenoic acid; e-cigarettes: electronic cigarettes; ECs: endothelial cells; ENDDs: electronic nicotine delivery devices; FDA: Food and Drug Administration; FSPTCA: family Smoking Prevention and Tobacco Control Act: GSH: glutathione; $\mathrm{H}_{2} \mathrm{~S}$ : hydrogen sulfide nitric oxide; $\mathrm{HCN}$ : hydrogen cyanide; HIV: human immunodeficiency virus; HMGB1: high mobility group protein B1; IR: ischemia reperfusion; JAM: junctional adhesion molecules-; MRI: magnetic resonance imaging; MRP4: multidrug resistance associate protein 4; MS: multiple sclerosis; NAB: N-nitrosoanabasine; NAT: N-nitrosoanabatine; NF: nicotine free; NFEL2 or Nrf2: nuclear factor (erythroid derived 2) like 2; NIOSH: National Institute for Occupational Safety and Health; NNK: 4-(methylnitrosamino)-1-(3pyridyl)-1-butanone; NNN: nitrosonornicotine; NO: nitric oxide; NQO1: NAD(P) $\mathrm{H}$ : quinone reductase I; NRTs: nicotine replacement therapies; $\mathrm{O}_{2}$ : oxygen; PAH: poly aromatic hydrocarbons; PG: propylene glycol; P-gp: P-glycoprotein; PXR: pregnane $X$ receptor; $\mathrm{RDA}$ : recommended dietary allowance; ROS: reactive oxidative species; SCl: silent cerebral infarction; SVID: small vessel ischemic disease; TPM: total particulate matter; TS: tobacco smoke; TSNAs: tobacco specific nitrosamines; ULN: ultralow nicotine; VEGF: vascular endothelial growth factor; VG: vegetable glycerin; VOC: volatile organic compounds; ZO-1: zonulae occludentes.
\end{abstract}

\section{Authors' contributions}

Pooja Naik drafted the review and Luca Cucullo supervised the work and provided guidance during manuscript preparation and revisions. All authors have read and approved the final version of the manuscript.

\section{Author details \\ ${ }^{1}$ Department of Pharmaceutical Sciences, Texas Tech University Health Sci- ences Center, School of Pharmacy, 1300 S. Coulter Street, Amarillo, TX 79106, USA. ${ }^{2}$ Center for Blood Brain Barrier Research, Texas Tech University Health Sciences Center, Amarillo, TX 79106, USA.}

\section{Acknowledgements}

Manuscript preparation was supported in part by NIH/NIDA R01-DA029121$01 \mathrm{~A} 1$ and Alternative Research Development Foundation Grants received by Luca Cucullo.

\section{Competing interests}

The authors declare that they have no competing interests.

Received: 13 August 2015 Accepted: 20 October 2015

Published online: 31 October 2015

\section{References}

1. Smoking-attributable mortality, years of potential life lost, and productivity losses-United States, 2000-2004. MMWR Morb Mortal Wkly Rep 2008;57:1226-1228

2. Who Report on The Global Tobacco Epidemic, 2013

3. Hecht SS. Cigarette smoking: cancer risks, carcinogens, and mechanisms. Langenbecks Arch Surg. 2006;391:603-13.

4. Messner B, Bernhard D. Smoking and cardiovascular disease: mechanisms of endothelial dysfunction and early atherogenesis. Arterioscler Thromb Vasc Biol. 2014;34:509-15.

5. National Center For Chronic Disease Prevention and Health Promotion (US) Office on Smoking and Health. Surgeon general's report: the health consequences of smoking - 50 years of progress. Atlanta, GA: Centers for Disease Control and Prevention (US); 2014

6. Howard G, Wagenknecht LE, Cai J, Cooper L, Kraut MA, Toole JF. Cigarette smoking and other risk factors for silent cerebral infarction in the general population. Stroke. 1998;29:913-7.

7. Mannami T, Iso H, Baba S, Sasaki S, Okada K, Konishi M, et al. Cigarette smoking and risk of stroke and its subtypes among middleaged Japanese men and women: the JPHC Study Cohort I. Stroke. 2004;35:1248-53.

8. Miller GJ, Bauer KA, Cooper JA, Rosenberg RD. Activation of the coagulant pathway in cigarette smokers. Thromb Haemost. 1998;79:549-53.

9. Mast H, Thompson JL, Lin IF, Hofmeister C, Hartmann A, Marx P, et al. Cigarette smoking as a determinant of high-grade carotid artery stenosis in Hispanic, black, and white patients with stroke or transient ischemic attack. Stroke. 1998;29:908-12.

10. Chalouhi N, Ali MS, Starke RM, Jabbour PM, Tjoumakaris SI, Gonzalez $L F$, et al. Cigarette smoke and inflammation: role in cerebral aneurysm formation and rupture. Mediators Inflamm. 2012;2012:271582.

11. Salzer J, Hallmans G, Nystrom M, Stenlund H, Wadell G, Sundstrom P. Smoking as a risk factor for multiple sclerosis. Mult Scler. 2013;19:1022-7.

12. Hedstrom AK, Hillert J, Olsson T, Alfredsson L. Smoking and multiple sclerosis susceptibility. Eur J Epidemiol. 2013;28:867-74.

13. Chang RC, Ho YS, Wong S, Gentleman SM, Ng HK. Neuropathology of cigarette smoking. Acta Neuropathol 2013.

14. Piao WH, Campagnolo D, Dayao C, Lukas RJ, Wu J, Shi FD. Nicotine and inflammatory neurological disorders. Acta Pharmacol Sin. 2009:30:715-22.

15. Abbott NJ, Revest PA, Romero IA. Astrocyte-endothelial interaction: physiology and pathology. Neuropathol Appl Neurobiol. 1992;18:424-33.

16. Abbott NJ. Astrocyte-endothelial interactions and blood-brain barrier permeability. J Anat. 2002;200:629-38.

17. Abbott NJ, Patabendige AA, Dolman DE, Yusof SR, Begley DJ. Structure and function of the blood-brain barrier. Neurobiol Dis. 2010;37:13-25.

18. Wolburg H, Lippoldt A. Tight junctions of the blood-brain barrier: development, composition and regulation. Vascul Pharmacol. 2002;38:323-37

19. Naik $P$, Cucullo L. In vitro blood-brain barrier models: current and perspective technologies. J Pharm Sci. 2012;101:1337-54

20. Schinkel AH. P-Glycoprotein, a gatekeeper in the blood-brain barrier. Adv Drug Deliv Rev. 1999;36:179-94.

21. O'Kane RL, Hawkins RA. $\mathrm{Na}^{+}$-dependent transport of large neutral amino acids occurs at the abluminal membrane of the blood-brain barrier. Am J Physiol Endocrinol Metab. 2003;285:E1167-73.

22. Roberts LM, Black DS, Raman C, Woodford K, Zhou M, Haggerty JE, et al. Subcellular localization of transporters along the rat blood-brain barrier and blood-cerebral-spinal fluid barrier by in vivo biotinylation. Neuroscience. 2008;155:423-38. 
23. Abbruscato TJ, Davis TP. Protein expression of brain endothelial cell E-cadherin after hypoxia/aglycemia: influence of astrocyte contact. Brain Res. 1999;842:277-86.

24. Bazzoni G, Dejana E. Endothelial cell-to-cell junctions: molecular organization and role in vascular homeostasis. Physiol Rev. 2004;84:869-901.

25. Tournier N, Chevillard L, Megarbane B, Pirnay S, Scherrmann JM, Decleves $X$. Interaction of drugs of abuse and maintenance treatments with human P-glycoprotein (ABCB1) and breast cancer resistance protein (ABCG2). Int J Neuropsychopharmacol. 2010;13:905-15.

26. Robey RW, To KK, Polgar O, Dohse M, Fetsch P, Dean M, et al. ABCG2: a perspective. Adv Drug Deliv Rev. 2009;61:3-13.

27. Hagenbuch B, Gao B, Meier PJ. Transport of xenobiotics across the blood-brain barrier. News Physiol Sci. 2002;17:231-4.

28. Ghosh C, Marchi N, Desai NK, Puvenna V, Hossain M, Gonzalez-Martinez $J$, et al. Cellular localization and functional significance of CYP3A4 in the human epileptic brain. Epilepsia. 2011;52:562-71.

29. Ghosh C, Gonzalez-Martinez J, Hossain M, Cucullo L, Fazio V, Janigro D, et al. Pattern of P450 expression at the human blood-brain barrier: roles of epileptic condition and laminar flow. Epilepsia 2010.

30. Dutheil F, Jacob A, Dauchy S, Beaune P, Scherrmann JM, Decleves X, et al. ABC transporters and cytochromes P450 in the human central nervous system: influence on brain pharmacokinetics and contribution to neurodegenerative disorders. Expert Opin Drug Metab Toxicol. 2010;6:1161-74

31. Khanna A, Guo M, Mehra M, Royal W III. Inflammation and oxidative stress induced by cigarette smoke in Lewis rat brains. J Neuroimmunol. 2013;254:69-75.

32. Gonsette RE. Neurodegeneration in multiple sclerosis: the role of oxidative stress and excitotoxicity. J Neurol Sci 2008.

33. Holmoy T, Hestvik AL. Multiple sclerosis: immunopathogenesis and controversies in defining the cause. Curr Opin Infect Dis. 2008;21:271-8.

34. Cojocaru IM, Cojocaru M, Sapira V, Ionescu A. Evaluation of oxidative stress in patients with acute ischemic stroke. Rom J Intern Med. 2013;51:97-106.

35. Huang J, Upadhyay UM, Tamargo RJ. Inflammation in stroke and focal cerebral ischemia. Surg Neurol. 2006;66:232-45.

36. Bennett S, Grant MM, Aldred S. Oxidative stress in vascular dementia and Alzheimer's disease: a common pathology. J Alzheimers Dis. 2009; 17:245-57

37. Shoamanesh A, Preis SR, Beiser AS, Vasan RS, Benjamin EJ, Kase CS, et al. Inflammatory biomarkers, cerebral microbleeds, and small vessel disease: framingham Heart Study. Neurology. 2015;84:825-32.

38. Wardlaw JM, Smith C, Dichgans M. Mechanisms of sporadic cerebral small vessel disease: insights from neuroimaging. Lancet Neurol. 2013;12:483-97.

39. Deane R, Zlokovic BV. Role of the blood-brain barrier in the pathogenesis of Alzheimer's disease. Curr Alzheimer Res. 2007:4:191-7.

40. Oby E, Janigro D. The blood-brain barrier and epilepsy. Epilepsia. 2006;47:1761-74.

41. Hossain M, Sathe T, Fazio V, Mazzone P, Weksler B, Janigro D, et al. Tobacco smoke: a critical etiological factor for vascular impairment at the blood-brain barrier. Brain Res. 2009;1287:192-205.

42. Marchi N, Cavaglia M, Fazio V, Bhudia S, Hallene K, Janigro D. Peripheral markers of blood-brain barrier damage. Clin Chim Acta. 2004;342:1-12

43. Marchi N, Rasmussen P, Kapural M, Fazio V, Kight K, Mayberg MR, et al. Peripheral markers of brain damage and blood-brain barrier dysfunction. Restor Neurol Neurosci. 2003;21:109-21.

44. Kanner AA, Marchi N, Fazio V, Mayberg MR, Koltz MT, Siomin V, et al. Serum S100beta: a noninvasive marker of blood-brain barrier function and brain lesions. Cancer. 2003;97:2806-13.

45. Naik P, Fofaria N, Prasad S, Sajja RK, Weksler B, Couraud PO, et al. Oxidative and pro-inflammatory impact of regular and denicotinized cigarettes on blood brain barrier endothelial cells: is smoking reduced or nicotine-free products really safe? BMC Neurosci. 2014;15:51.

46. Naik P, Sajja RK, Prasad S, Cucullo L. Effect of full flavor and denicotinized cigarettes exposure on the brain microvascular endothelium: a microarray-based gene expression study using a human immortalized BBB endothelial cell line. BMC Neurosci. 2015;16:38.

47. Kaplanski G, Marin V, Fabrigoule M, Boulay V, Benoliel AM, Bongrand P, et al. Thrombin-activated human endothelial cells support monocyte adhesion in vitro following expression of intercellular adhesion molecule-1 (ICAM-1; CD54) and vascular cell adhesion molecule-1 (VCAM-1; CD106). Blood. 1998;92:1259-67.

48. Tuttolomondo A, Di Raimondo D, di Sciacca R, Pinto A, Licata G. Inflammatory cytokines in acute ischemic stroke. Curr Pharm Des. 2008;14:3574-89.

49. Gloor SM, Wachtel M, Bolliger MF, Ishihara H, Landmann R, Frei K. Molecular and cellular permeability control at the blood-brain barrier Brain Res Brain Res Rev. 2001;36:258-64.

50. Sajja RK, Prasad S, Cucullo L. Impact of altered glycaemia on bloodbrain barrier endothelium: an in vitro study using the hCMEC/D3 cell line. Fluids Barriers CNS. 2014;11:8.

51. Abbruscato TJ, Lopez SP, Mark KS, Hawkins BT, Davis TP. Nicotine and cotinine modulate cerebral microvascular permeability and protein expression of ZO-1 through nicotinic acetylcholine receptors expressed on brain endothelial cells. J Pharm Sci. 2002;91:2525-38.

52. Abbruscato TJ, Lopez SP, Roder K, Paulson JR. Regulation of bloodbrain barrier $\mathrm{Na}, \mathrm{K}, 2 \mathrm{Cl}$-cotransporter through phosphorylation during in vitro stroke conditions and nicotine exposure. J Pharmacol Exp Ther. 2004;310:459-68.

53. Hutamekalin P, Farkas AE, Orbok A, Wilhelm I, Nagyoszi P, Veszelka S, et al. Effect of nicotine and polyaromtic hydrocarbons on cerebral endothelial cells. Cell Biol Int. 2008;32:198-209.

54. Paulson JR, Yang T, Selvaraj PK, Mdzinarishvili A, Van der Schyf CJ, Klein J, et al. Nicotine exacerbates brain edema during in vitro and in vivo focal ischemic conditions. J Pharmacol Exp Ther. 2010;332:371-9.

55. Paulson JR, Roder KE, McAfee G, Allen DD, Van der Schyf CJ, Abbruscato TJ. Tobacco smoke chemicals attenuate brain-to-blood potassium transport mediated by the $\mathrm{Na}, \mathrm{K}, 2 \mathrm{Cl}$-cotransporter during hypoxiareoxygenation. J Pharmacol Exp Ther. 2006;316:248-54.

56. Hawkins BT, Brown RC, Davis TP. Smoking and ischemic stroke: a role for nicotine? Trends Pharmacol Sci. 2002;23:78-82.

57. Manda VK, Mittapalli RK, Bohn KA, Adkins CE, Lockman PR. Nicotine and cotinine increases the brain penetration of saquinavir in rat. J Neurochem. 2010;115:1495-507.

58. Manda VK, Mittapalli RK, Geldenhuys WJ, Lockman PR. Chronic exposure to nicotine and saquinavir decreases endothelial Notch-4 expression and disrupts blood-brain barrier integrity. J Neurochem. 2010;115:515-25.

59. Lockman PR, Van der Schyf CJ, Abbruscato TJ, Allen DD. Chronic nicotine exposure alters blood-brain barrier permeability and diminishes brain uptake of methyllycaconitine. J Neurochem. 2005;94:37-44.

60. Masubuchi T, Koyama S, Sato E, Takamizawa A, Kubo K, Sekiguchi M, et al. Smoke extract stimulates lung epithelial cells to release neutrophil and monocyte chemotactic activity. Am J Pathol. 1998;153:1903-12.

61. Palmblad J. The role of granulocytes in inflammation. Scand J Rheumatol. 1984;13:163-72.

62. Togna AR, Latina V, Orlando R, Togna Gl. Cigarette smoke inhibits adenine nucleotide hydrolysis by human platelets. Platelets. 2008; 19:537-42.

63. Girdhar G, Xu S, Jesty J, Bluestein D. In vitro model of platelet-endothelial activation due to cigarette smoke under cardiovascular circulation conditions. Ann Biomed Eng. 2008;36:1142-51.

64. Strazielle N, Khuth ST, Murat A, Chalon A, Giraudon P, Belin MF, et al. Proinflammatory cytokines modulate matrix metalloproteinase secretion and organic anion transport at the blood-cerebrospinal fluid barrier. J Neuropathol Exp Neurol. 2003;62:1254-64.

65. Rosenberg GA. Matrix metalloproteinases in neuroinflammation. Glia. 2002;39:279-91.

66. Gidday JM, Gasche YG, Copin JC, Shah AR, Perez RS, Shapiro SD, et al. Leukocyte-derived matrix metalloproteinase- 9 mediates blood-brain barrier breakdown and is proinflammatory after transient focal cerebral ischemia. Am J Physiol Heart Circ Physiol. 2005;289:H558-68.

67. Romanic AM, White RF, Arleth AJ, Ohlstein EH, Barone FC. Matrix metalloproteinase expression increases after cerebral focal ischemia in rats: inhibition of matrix metalloproteinase-9 reduces infarct size. Stroke. 1998;29:1020-30.

68. Nordskog BK, Fields WR, Hellmann GM. Kinetic analysis of cytokine response to cigarette smoke condensate by human endothelial and monocytic cells. Toxicology. 2005;212:87-97.

69. Shen Y, Rattan V, Sultana C, Kalra VK. Cigarette smoke condensateinduced adhesion molecule expression and transendothelial migration of monocytes. Am J Physiol. 1996;270:H1624-33. 
70. Goldeck D, Larbi A, Pellicano M, Alam I, Zerr I, Schmidt C, et al. Enhanced Chemokine Receptor Expression on Leukocytes of Patients with Alzheimer's Disease. PLoS ONE. 2013;8:e66664.

71. Holman DW, Klein RS, Ransohoff RM. The blood-brain barrier, chemokines and multiple sclerosis. Biochim Biophys Acta 2010.

72. Chen SH, Murphy DA, Lassoued W, Thurston G, Feldman MD, Lee WM. Activated STAT3 is a mediator and biomarker of VEGF endothelial activation. Cancer Biol Ther. 2008;7:1994-2003.

73. Chen Z, Han ZC. STAT3: a critical transcription activator in angiogenesis. Med Res Rev. 2008;28:185-200

74. Xu Y, Yamada T, Satoh T, Okuda Y. Measurement of serum amyloid A1 (SAA1), a major isotype of acute phase SAA. Clin Chem Lab Med. 2006;44:59-63.

75. Abboud S, Viiri LE, Lutjohann D, Goebeler S, Luoto T, Friedrichs S, et al. Associations of apolipoprotein E gene with ischemic stroke and intracranial atherosclerosis. Eur J Hum Genet. 2008;16:955-60.

76. Borland C, Higenbottam T. Nitric oxide yields of contemporary UK, US and French cigarettes. Int J Epidemiol. 1987;16:31-4.

77. Wong D, Dorovini-Zis K, Vincent SR. Cytokines, nitric oxide, and CGMP modulate the permeability of an in vitro model of the human bloodbrain barrier. Exp Neurol. 2004;190:446-55.

78. Yamauchi A, Dohgu S, Nishioku T, Shuto H, Naito M, Tsuruo T, et al. An inhibitory role of nitric oxide in the dynamic regulation of the bloodbrain barrier function. Cell Mol Neurobiol. 2007;27:263-70.

79. Huang Z, Huang PL, Ma J, Meng W, Ayata C, Fishman MC, et al. Enlarged infarcts in endothelial nitric oxide synthase knockout mice are attenuated by nitro-L-arginine. J Cereb Blood Flow Metab. 1996;16:981-7.

80. Peluffo G, Calcerrada P, Piacenza L, Pizzano N, Radi R. Superoxide-mediated inactivation of nitric oxide and peroxynitrite formation by tobacco smoke in vascular endothelium: studies in cultured cells and smokers. Am J Physiol Heart Circ Physiol. 2009;296:H1781-92.

81. lizuka T, Ishii Y, Itoh K, Kiwamoto T, Kimura T, Matsuno Y, et al. Nrf2deficient mice are highly susceptible to cigarette smoke-induced emphysema. Genes Cells. 2005;10:1113-25.

82. Surh YJ, Kundu JK, Na HK. Nrf2 as a master redox switch in turning on the cellular signaling involved in the induction of cytoprotective genes by some chemopreventive phytochemicals. Planta Med. 2008;74:1526-39.

83. Hayes JD, Dinkova-Kostova AT. The Nrf2 regulatory network provides an interface between redox and intermediary metabolism. Trends Biochem Sci. 2014;39:199-218.

84. Bryan HK, Olayanju A, Goldring CE, Park BK. The Nrf2 cell defence pathway: keap1-dependent and-independent mechanisms of regulation. Biochem Pharmacol. 2013;85:705-17.

85. Nguyen T, Nioi P, Pickett CB. The Nrf2-antioxidant response element signaling pathway and its activation by oxidative stress. J Biol Chem. 2009;284:13291-5

86. Rochette L, Zeller M, Cottin Y, Vergely C. Diabetes, oxidative stress and therapeutic strategies. Biochim Biophys Acta. 2014;1840:2709-29.

87. Mushtaq G, Khan JA, Kumosani TA, Kamal MA. Alzheimer's disease and type 2 diabetes via chronic inflammatory mechanisms. Saudi J Biol Sci. 2015;22:4-13.

88. Zhou S, Sun Y, Zhuang Y, Zhao W, Chen Y, Jiang B, et al. Effects of Kallistatin on Oxidative Stress and Inflammation on Renal IschemiaReperfusion Injury in Mice. Curr Vasc Pharmacol 2015.

89. Pan H, He M, Liu R, Brecha NC, Yu AC, Pu M. Sulforaphane protects rodent retinas against ischemia-reperfusion injury through the activation of the Nrf2/HO-1 antioxidant pathway. PLOS ONE. 2014;9:e114186.

90. Voigt A, Rahnefeld A, Kloetzel PM, Kruger E. Cytokine-induced oxidative stress in cardiac inflammation and heart failure-how the ubiquitin proteasome system targets this vicious cycle. Front Physiol. 2013;4:42.

91. Poli G. Pathogenesis of liver fibrosis: role of oxidative stress. Mol Aspects Med. 2000;21:49-98.

92. Cachofeiro V, Goicochea M, de Vinuesa SG, Oubina P, Lahera V, Luno J. Oxidative stress and inflammation, a link between chronic kidney disease and cardiovascular disease. Kidney Int Suppl 2008, S4-S9.

93. Zuo L, He F, Sergakis GG, Koozehchian MS, Stimpfl JN, Rong Y, et al. Interrelated role of cigarette smoking, oxidative stress, and immune response in COPD and corresponding treatments. Am J Physiol Lung Cell Mol Physiol. 2014;307:L205-18.
94. Boutten A, Goven D, Artaud-Macari E, Boczkowski J, Bonay M. NRF2 targeting: a promising therapeutic strategy in chronic obstructive pulmonary disease. Trends Mol Med. 2011;17:363-71.

95. Malhotra D, Thimmulappa R, Navas-Acien A, Sandford A, Elliott M, Singh $A$, et al. Decline in NRF2-regulated antioxidants in chronic obstructive pulmonary disease lungs due to loss of its positive regulator, DJ-1. Am J Respir Crit Care Med. 2008:178:592-604.

96. Alfieri A, Srivastava S, Siow RC, Modo M, Fraser PA, Mann GE. Targeting the Nrf2-Keap1 antioxidant defence pathway for neurovascular protection in stroke. J Physiol. 2011;589:4125-36.

97. Chen G, Fang Q, Zhang J, Zhou D, Wang Z. Role of the Nrf2-ARE pathway in early brain injury after experimental subarachnoid hemorrhage. J Neurosci Res. 2011;89:515-23.

98. Petri S, Korner S, Kiaei M. Nrf2/ARE signaling pathway: key mediator in oxidative stress and potential therapeutic target in ALS. Neurol Res Int. 2012;2012:878030

99. Lee DH, Gold R, Linker RA. Mechanisms of oxidative damage in multiple sclerosis and neurodegenerative diseases: therapeutic modulation via fumaric acid esters. Int J Mol Sci. 2012;13:11783-803.

100. Sandberg M, Patil J, D'Angelo B, Weber SG, Mallard C. NRF2-regulation in brain health and disease: implication of cerebral inflammation. Neuropharmacology. 2014;79:298-306.

101. Prasad S, Sajja RK, Naik P, Cucullo L. Diabetes mellitus and blood-brain barrier dysfunction: an overview. J Pharmacovigil. 2014;2:125.

102. Prasad S, Sajja RK, Park JH, Naik P, Kaisar MA, Cucullo L. Impact of cigarette smoke extract and hyperglycemic conditions on blood-brain barrier endothelial cells. Fluids Barriers CNS. 2015;12:18.

103. Chang CY, Kuan YH, Li JR, Chen WY, Ou YC, Pan HC, et al. Docosahexaenoic acid reduces cellular inflammatory response following permanent focal cerebral ischemia in rats. J Nutr Biochem. 2013;24:2127-37.

104. Ren J, Fan C, Chen N, Huang J, Yang Q. Resveratrol pretreatment attenuates cerebral ischemic injury by upregulating expression of transcription factor Nrf2 and HO-1 in rats. Neurochem Res. 2011;36:2352-62.

105. Zhang J, Fu B, Zhang X, Zhang L, Bai X, Zhao X, et al. Bicyclol upregulates transcription factor $\mathrm{Nrf2}, \mathrm{HO}-1$ expression and protects rat brains against focal ischemia. Brain Res Bull. 2014;100:38-43.

106. Cantin AM. Cellular response to cigarette smoke and oxidants: adapting to survive. Proc Am Thorac Soc. 2010;7:368-75.

107. Tuder RM, Petrache I. Pathogenesis of chronic obstructive pulmonary disease. J Clin Invest. 2012;122:2749-55.

108. Garbin U, Fratta PA, Stranieri C, Cominacini M, Pasini A, Manfro S, et al. Cigarette smoking blocks the protective expression of Nrf2/ARE pathway in peripheral mononuclear cells of young heavy smokers favouring inflammation. PLoS ONE. 2009:4:e8225.

109. Chen HW, Chien ML, Chaung YH, Lii CK, Wang TS. Extracts from cigarette smoke induce DNA damage and cell adhesion molecule expression through different pathways. Chem Biol Interact. 2004;150:233-41.

110. Pryor WA, Stone K, Zang LY, Bermudez E. Fractionation of aqueous cigarette tar extracts: fractions that contain the tar radical cause DNA damage. Chem Res Toxicol. 1998;11:441-8.

111. Stone K, Bermudez E, Zang LY, Carter KM, Queenan KE, Pryor WA. The ESR properties, DNA nicking, and DNA association of aged solutions of catechol versus aqueous extracts of tar from cigarette smoke. Arch Biochem Biophys. 1995;319:196-203.

112. DeMarini DM. Genotoxicity of tobacco smoke and tobacco smoke condensate: a review. Mutat Res. 2004;567:447-74.

113. Hayes JD, Strange RC. Potential contribution of the glutathione S-transferase supergene family to resistance to oxidative stress. Free Radic Res. 1995;22:193-207.

114. Chiu HJ, Fischman DA, Hammerling U. Vitamin A depletion causes oxidative stress, mitochondrial dysfunction, and PARP-1-dependent energy deprivation. FASEB J. 2008;22:3878-87.

115. Tsuneki H, Sekizaki N, Suzuki T, Kobayashi S, Wada T, Okamoto T, et al Coenzyme Q10 prevents high glucose-induced oxidative stress in human umbilical vein endothelial cells. Eur J Pharmacol. 2007;566:1-10.

116. Gallo C, Renzi P, Loizzo S, Loizzo A, Piacente S, Festa M, et al. Potential therapeutic effects of vitamin $E$ and $C$ on placental oxidative stress induced by nicotine: an in vitro evidence. Open Biochem J. 2010;4:77-82.

117. Davitashvili DT, Museridze DP, Svanidze IK, Pavliashvili NS, Sanikidze TV Correction of oxidative stress in the rat brain cortical cellular culture with vitamines E and C. Georgian Med News 2010;56-60. 
118. Sobczak A, Golka D, Szoltysek-Boldys I. The effects of tobacco smoke on plasma alpha- and gamma-tocopherol levels in passive and active cigarette smokers. Toxicol Lett. 2004;151:429-37.

119. Dietrich M, Block G, Norkus EP, Hudes M, Traber MG, Cross CE, et al. Smoking and exposure to environmental tobacco smoke decrease some plasma antioxidants and increase gamma-tocopherol in vivo after adjustment for dietary antioxidant intakes. Am J Clin Nutr. 2003;77:160-6.

120. Tsuchiya M, Asada A, Kasahara E, Sato EF, Shindo M, Inoue M. Smoking a single cigarette rapidly reduces combined concentrations of nitrate and nitrite and concentrations of antioxidants in plasma. Circulation. 2002;105:1155-7.

121. Polidori MC, Nelles G. Antioxidant clinical trials in mild cognitive impairment and Alzheimer's disease_challenges and perspectives. Curr Pharm Des. 2014:20:3083-92.

122. Calabrese V, Cornelius C, Leso V, Trovato-Salinaro A, Ventimiglia B, Cavallaro $M$, et al. Oxidative stress, glutathione status, sirtuin and cellular stress response in type 2 diabetes. Biochim Biophys Acta. 2012;1822:729-36

123. Johri A, Beal MF. Antioxidants in Huntington's disease. Biochim Biophys Acta. 2012;1822:664-74.

124. Weber CA, Ernst ME. Antioxidants, supplements, and Parkinson's disease. Ann Pharmacother. 2006;40:935-8.

125. Cherubini A, Ruggiero C, Morand C, Lattanzio F, Dell'aquila G, Zuliani $\mathrm{G}$, et al. Dietary antioxidants as potential pharmacological agents for ischemic stroke. Curr Med Chem. 2008;15:1236-48.

126. Pun PB, Lu J, Moochhala S. Involvement of ROS in BBB dysfunction. Free Radic Res. 2009:43:348-64

127. Hossain M, Mazzone P, Tierney W, Cucullo L. In vitro assessment of tobacco smoke toxicity at the BBB: do antioxidant supplements have a protective role? BMC Neurosci. 2011;12:92.

128. Traber MG, van d, V, Reznick AZ, Cross CE. Tobacco-related diseases. Is there a role for antioxidant micronutrient supplementation? Clin Chest Med 2000;21:173-87.

129. Johnston CS, Martin LJ, Cai X. Antihistamine effect of supplemental ascorbic acid and neutrophil chemotaxis. J Am Coll Nutr. 1992;11:172-6.

130. Koul A, Singh A, Sandhir R. Effect of alpha-tocopherol on the cardiac antioxidant defense system and atherogenic lipids in cigarette smokeinhaling mice. Inhal Toxicol. 2003;15:513-22.

131. Al-Malki AL, Moselhy SS. Protective effect of vitamin E and epicatechin against nicotine-induced oxidative stress in rats. Toxicol Ind Health. 2013;29:202-8.

132. Gumustekin K, Taysi S, Alp HH, Aktas O, Oztasan N, Akcay F, et al. Vitamin E and Hippophea rhamnoides L. extract reduce nicotine-induced oxidative stress in rat heart. Cell Biochem Funct. 2010;28:329-33.

133. Gupta S, Sharma TK, Kaushik GG, Shekhawat VP. Vitamin E supplementation may ameliorate oxidative stress in type 1 diabetes mellitus patients. Clin Lab. 2011:57:379-86.

134. dos Santos PS, Costa JP, Tome AR, Saldanha GB, de Souza GF, Feng D, et al. Oxidative stress in rat striatum after pilocarpine-induced seizures is diminished by alpha-tocopherol. Eur J Pharmacol. 2011;668:65-71.

135. Venditti P, Napolitano G, Di SL, Agnisola C, Di MS. Effect of vitamin E administration on response to ischaemia-reperfusion of hearts from cold-exposed rats. Exp Physiol. 2011;96:635-46.

136. Arato E, Kurthy M, Sinay L, Kasza G, Menyhei G, Hardi P, et al. Effect of vitamin $E$ on reperfusion injuries during reconstructive vascular operations on lower limbs. Clin Hemorheol Microcirc. 2010;44:125-36.

137. Abdul-Aziz A, MacEwan DJ, Bowles KM, Rushworth SA. Oxidative stress responses and NRF2 in human leukaemia. Oxid Med Cell Longev. 2015;2015:454659.

138. Muller T, Hengstermann A. Nrf2: friend and foe in preventing cigarette smoking-dependent lung disease. Chem Res Toxicol. 2012;25:1805-24.

139. Zhang J, Takahashi HK, Liu K, Wake H, Liu R, Maruo T, et al. Anti-high mobility group box-1 monoclonal antibody protects the bloodbrain barrier from ischemia-induced disruption in rats. Stroke. 2011:42:1420-8.

140. Okuma Y, Liu K, Wake H, Zhang J, Maruo T, Date I, et al. Anti-high mobility group box-1 antibody therapy for traumatic brain injury. Ann Neurol. 2012;72:373-84

141. Sapojnikova N, Kartvelishvili T, Asatiani N, Zinkevich V, Kalandadze I, Gugutsidze D, et al. Correlation between MMP-9 and extracellular cytokine HMGB1 in prediction of human ischemic stroke outcome. Biochim Biophys Acta 2014.

142. Tang D, Kang R, Zeh HJ III, Lotze MT. High-mobility group box 1, oxidative stress, and disease. Antioxid Redox Signal. 2011;14:1315-35.

143. Tang D, Billiar TR, Lotze MT. A Janus tale of two active high mobility group box 1 (HMGB1) redox states. Mol Med. 2012;18:1360-2.

144. How Tobacco Smoke Causes Disease. The biology and behavioral basis for smoking-attributable disease: a report of the surgeon general. Chapter 3. Publications and Reports of the Surgeon General 2010.

145. Talhout R, Schulz T, Florek E, van BJ, Wester P. Opperhuizen a: hazardous compounds in tobacco smoke. Int J Environ Res Public Health. 2011;8:613-28.

146. Aravamudan B, Kiel A, Freeman M, Delmotte $\mathrm{P}$, Thompson M, Vassallo $R$, et al. Cigarette smoke-induced mitochondrial fragmentation and dysfunction in human airway smooth muscle. Am J Physiol Lung Cell Mol Physiol. 2014;306:L840-54

147. Mansoor S, Gupta N, Falatoonzadeh P, Kuppermann BD, Kenney MC. 2-ethylpyridine, a cigarette smoke component, causes mitochondrial damage in human retinal pigment epithelial cells in vitro. Indian J Ophthalmol. 2014;62:16-22.

148. Naserzadeh P, Hosseini MJ, Mohamadzadeh AB, Pourahmad J. Toxicity mechanisms of cigarette smoke on mouse fetus mitochondria. Iran J Pharm Res. 2015;14:131-8.

149. van der Toorn M, Rezayat D, Kauffman HF, Bakker SJ, Gans RO, Koeter $\mathrm{GH}$, et al. Lipid-soluble components in cigarette smoke induce mitochondrial production of reactive oxygen species in lung epithelial cells. Am J Physiol Lung Cell Mol Physiol. 2009;297:L109-14.

150. Aoshiba K, Koinuma M, Yokohori N, Nagai A. Immunohistochemical evaluation of oxidative stress in murine lungs after cigarette smoke exposure. Inhal Toxicol. 2003;15:1029-38.

151. Rahman I, van Schadewijk AA, Crowther AJ, Hiemstra PS, Stolk J, MacNee W, et al. 4-Hydroxy-2-nonenal, a specific lipid peroxidation product, is elevated in lungs of patients with chronic obstructive pulmonary disease. Am J Respir Crit Care Med. 2002;166:490-5

152. Miller ER III, Appel LJ, Jiang L, Risby TH. Association between cigarette smoking and lipid peroxidation in a controlled feeding study. Circulation. 1997;96:1097-101.

153. Lin CC, Su TH, Wang TS. Protein carbonylation in THP-1 cells induced by cigarette smoke extract via a copper-catalyzed pathway. Chem Res Toxicol. 2009:22:1232-8.

154. Yao H, Sundar IK, Ahmad T, Lerner C, Gerloff J, Friedman AE, et al. SIRT1 protects against cigarette smoke-induced lung oxidative stress via a FOXO3-dependent mechanism. Am J Physiol Lung Cell Mol Physiol. 2014;306:L816-28.

155. Vadhanam MV, Thaiparambil J, Gairola CG, Gupta RC. Oxidative DNA adducts detected in vitro from redox activity of cigarette smoke constituents. Chem Res Toxicol. 2012;25:2499-504.

156. Sajja RK, Naik P, Cucullo L. differential cerebrovascular toxicity of various tobacco products: a regulatory perspective. J Pharmacovigil 2015;3.

157. Chen IL. FDA summary of adverse events on electronic cigarettes. Nicotine Tob Res. 2013;15:615-6.

158. Farsalinos KE, Spyrou A, Tsimopoulou K, Stefopoulos C, Romagna G, Voudris V. Nicotine absorption from electronic cigarette use: comparison between first and new-generation devices. Sci Rep. 2014;4:4133.

159. Varlet V, Farsalinos K, Augsburger M, Thomas A, Etter JF. Toxicity assessment of refill liquids for electronic cigarettes. Int J Environ Res Public Health. 2015;12:4796-815.

160. Behar RZ, Davis B, Wang Y, BahI V, Lin S, Talbot P. Identification of toxicants in cinnamon-flavored electronic cigarette refill fluids. Toxicol In Vitro 2013.

161. Orr MS: Electronic cigarettes in the USA: a summary of available toxicology data and suggestions for the future. Tob Control 2014;23(Suppl 2):ii18-ii22.

162. Tierney PA, Karpinski CD, Brown JE, Luo W, Pankow JF. Flavour chemicals in electronic cigarette fluids. Tob Control 2015.

163. King BA, Alam S, Promoff G, Arrazola R, Dube SR. Awareness and everuse of electronic cigarettes among U.S. adults, 2010-2011. Nicotine Tob Res. 2013;15:1623-7.

164. E-cigarette use triples among middle and high school students in just one year. 4-16-2015. Center for Control Disease and Prevention. 
165. Farsalinos KE, Romagna G, Tsiapras D, Kyrzopoulos S, Voudris V. Evaluating nicotine levels selection and patterns of electronic cigarette use in a group of "vapers" who had achieved complete substitution of smoking. Subst Abuse. 2013;7:139-46.

166. Fagerstrom K. Determinants of tobacco use and renaming the FTND to the fagerstrom test for cigarette dependence. Nicotine Tob Res. 2012;14:75-8.

167. Vansickel AR, Weaver MF, Eissenberg T. Clinical laboratory assessment of the abuse liability of an electronic cigarette. Addiction. 2012;107:1493-500

168. Vansickel AR, Cobb CO, Weaver MF, Eissenberg TE. A clinical laboratory model for evaluating the acute effects of electronic "cigarettes": nicotine delivery profile and cardiovascular and subjective effects. Cancer Epidemiol Biomarkers Prev. 2010;19:1945-53.

169. Bullen C, McRobbie H, Thornley S, Glover M, Lin R, Laugesen M. Effect of an electronic nicotine delivery device (e cigarette) on desire to smoke and withdrawal, user preferences and nicotine delivery: randomised cross-over trial. Tob Control. 2010;19:98-103.

170. Blank MD, Sams C, Weaver MF, Eissenberg T. Nicotine delivery, cardiovascular profile, and subjective effects of an oral tobacco product for smokers. Nicotine Tob Res. 2008;10:417-21.

171. Cox LS, Tiffany ST, Christen AG. Evaluation of the brief questionnaire of smoking urges (QSU-brief) in laboratory and clinical settings. Nicotine Tob Res. 2001;3:7-16.

172. Hua M, Yip H, Talbot P. Mining data on usage of electronic nicotine delivery systems (ENDS) from YouTube videos. Tob Control. 2013;22:103-6.

173. Shiffman S, Dunbar M, Kirchner T, Li X, Tindle H, Anderson S, et al. Smoker reactivity to cues: effects on craving and on smoking behavior. J Abnorm Psychol. 2013;122:264-80.

174. Romagna G, Allifranchini E, Bocchietto E, Todeschi S, Esposito M, Farsalinos KE. Cytotoxicity evaluation of electronic cigarette vapor extract on cultured mammalian fibroblasts (ClearStream-LIFE): comparison with tobacco cigarette smoke extract. Inhal Toxicol. 2013:25:354-61.

175. Cervellati F, Muresan XM, Sticozzi C, Gambari R, Montagner G, Forman $\mathrm{HJ}$, et al. Comparative effects between electronic and cigarette smoke in human keratinocytes and epithelial lung cells. Toxicol In Vitro. 2014;28:999-1005.
176. Bahl V, Lin S, Xu N, Davis B, Wang YH, Talbot P. Comparison of electronic cigarette refill fluid cytotoxicity using embryonic and adult models. Reprod Toxicol. 2012;34:529-37.

177. Cheng T. Chemical evaluation of electronic cigarettes. Tob Control 2014;23(Suppl 2):ii11-ii17.

178. Bahl V, Lin S, Xu N, Davis B, Wang YH, Talbot P. Comparison of electronic cigarette refill fluid cytotoxicity using embryonic and adult models. Reprod Toxicol. 2012;34:529-37.

179. Lerner CA, Sundar IK, Watson RM, Elder A, Jones R, Done D, et al. Environmental health hazards of e-cigarettes and their components: oxidants and copper in e-cigarette aerosols. Environ Pollut. 2015;198:100-7.

180. Scheffler S, Dieken H, Krischenowski O, Forster C, Branscheid D, Aufderheide M. Evaluation of E-cigarette liquid vapor and mainstream cigarette smoke after direct exposure of primary human bronchial epithelial cells. Int J Environ Res Public Health. 2015;12:3915-25.

181. Lerner CA, Sundar IK, Yao H, Gerloff J, Ossip DJ, Mclntosh S, et al. Vapors produced by electronic cigarettes and e-juices with flavorings induce toxicity, oxidative stress, and inflammatory response in lung epithelial cells and in mouse lung. PLoS ONE. 2015;10:e0116732.

182. Farsalinos KE, Romagna G, Tsiapras D, Kyrzopoulos S, Voudris V. Characteristics, perceived side effects and benefits of electronic cigarette use: a worldwide survey of more than 19,000 consumers. Int J Environ Res Public Health. 2014;11:4356-73.

183. McRobbie H, Bullen C, Hartmann-Boyce J, Hajek P. Electronic cigarettes for smoking cessation and reduction. Cochrane Database Syst Rev 2014;12:CD010216.

184. Pokhrel P, Little MA, Fagan P, Kawamoto CT, Herzog TA. Correlates of use of electronic cigarettes versus nicotine replacement therapy for help with smoking cessation. Addict Behav. 2014;39:1869-73.

185. Kelly TN, Gu D, Chen J, Huang JF, Chen JC, Duan X, et al. Cigarette smoking and risk of stroke in the chinese adult population. Stroke. 2008;39:1688-93.

186. Hernan MA, Olek MJ, Ascherio A. Cigarette smoking and incidence of multiple sclerosis. Am J Epidemiol. 2001;154:69-74.

187. Alfieri A, Srivastava S, Siow RC, Cash D, Modo M, Duchen MR, et al. Sulforaphane preconditioning of the $\mathrm{Nrf} / \mathrm{HO}-1$ defense pathway protects the cerebral vasculature against blood-brain barrier disruption and neurological deficits in stroke. Free Radic Biol Med. 2013;65:1012-22

\section{Submit your next manuscript to BioMed Central and take full advantage of:}

- Convenient online submission

- Thorough peer review

- No space constraints or color figure charges

- Immediate publication on acceptance

- Inclusion in PubMed, CAS, Scopus and Google Scholar

- Research which is freely available for redistribution

Submit your manuscript at 